University of Nebraska - Lincoln

DigitalCommons@University of Nebraska - Lincoln

USDA Forest Service / UNL Faculty Publications U.S. Department of Agriculture: Forest Service -National Agroforestry Center

$9-2012$

\title{
Predicting Live and Dead Tree Basal Area in Bark Beetle-Affected Forests from Discrete-Return LiDAR
}

\author{
Andrew T. Hudak \\ Rocky Mountain Research Station, ahudak@fs.fed.us \\ Benjamin C. Bright \\ University of Idaho, bright@uidaho.edu \\ Jose Negron \\ Rocky Mountain Research Station, jnegron@fs.fed.us \\ Robert McGaughey \\ Pacific Northwest Research Station, bmcgaughey@fs.fed.us \\ Hans-Erik Andersen \\ Pacific Northwest Research Station, handersen@fs.fed.us \\ See next page for additional authors
}

Follow this and additional works at: https://digitalcommons.unl.edu/usdafsfacpub

Hudak, Andrew T.; Bright, Benjamin C.; Negron, Jose; McGaughey, Robert; Andersen, Hans-Erik; and Hicke, Jeffrey A., "Predicting Live and Dead Tree Basal Area in Bark Beetle-Affected Forests from Discrete-Return LiDAR" (2012). USDA Forest Service / UNL Faculty Publications. 218.

https://digitalcommons.unl.edu/usdafsfacpub/218

This Article is brought to you for free and open access by the U.S. Department of Agriculture: Forest Service -National Agroforestry Center at DigitalCommons@University of Nebraska - Lincoln. It has been accepted for inclusion in USDA Forest Service / UNL Faculty Publications by an authorized administrator of DigitalCommons@University of Nebraska - Lincoln. 
Authors

Andrew T. Hudak, Benjamin C. Bright, Jose Negron, Robert McGaughey, Hans-Erik Andersen, and Jeffrey A. Hicke 


\title{
Predicting Live and Dead Tree Basal Area in Bark Beetle-Affected Forests from Discrete-Return LiDAR
}

\author{
Andrew T. Hudak ${ }^{1}$, Ben Bright ${ }^{2}$, Jose Negron ${ }^{3}$, Robert McGaughey ${ }^{4}$, Hans-Erik \\ Andersen $^{5}$, Jeffrey A. Hicke ${ }^{6}$ \\ ${ }^{1}$ U.S. Forest Service, Rocky Mountain Research Station, ahudak@fs.fed.us \\ ${ }^{2}$ University of Idaho, Department of Geography, bright@uidaho.edu \\ ${ }^{3}$ U.S. Forest Service, Rocky Mountain Research Station, jnegron@,fs.fed.us \\ ${ }^{4}$ U.S. Forest Service, Pacific Northwest Research Station, bmcgaughey@,fs.fed.us \\ ${ }^{5}$ U.S. Forest Service, Pacific Northwest Research Station, handersen@ffs.fed.us \\ ${ }^{6}$ University of Idaho, Department of Geography, jhicke@uidaho.edu
}

Paper Number: \#\#\#SL2012-139

\section{Introduction}

Recent bark beetle outbreaks in western North America have been widespread and severe. High tree mortality due to bark beetles affects the fundamental ecosystem processes of primary production and decomposition that largely determine carbon balance (Kurz et al. 2008, Pfeifer et al. 2011, Hicke et al. 2012). Forest managers need accurate data on beetle-induced tree mortality to make better decisions on how best to remediate beetle-affected forests and restore healthy ecosystem services (Negron et al. 2008). Discrete-return LiDAR measures canopy height and density, and LiDAR intensity provides some indication of the spectral reflectance and condition of canopy elements (foliage and branches) (Kim et al. 2009). LiDAR has been successfully applied to estimate biomass and carbon stocks in healthy forest (Hudak et al. 2012) and beetle-affected forest (Bright et al. 2012). A challenge in beetle-affected forests is that most airborne LiDAR has a single near infrared wavelength; i.e., LiDAR lacks the multispectral information useful for distinguishing between green, red, and grey trees. However, LiDAR intensity values may help distinguish between live green and dead red or grey trees. Moreover, mountain pine beetles (the most widespread bark beetle currently) and spruce beetles preferentially attack larger trees, so beetles impart a canopy structural signature that may be exploited (Coops et al. 2009).

Our objective is to predict Live and Dead Basal Area (BA) in beetle-affected areas in five states in the USA using canopy height, density, intensity, and topographic metrics derived from discrete-return airborne LiDAR data, tree measurements collected in field plots and summarized into plot-level estimates of Live BA and Dead BA using the Forest Vegetation Simulator (FVS), and the nonparametric Random Forests (RF) machine learning algorithm (Breiman 2001). Predicting both Live and Dead BA in bark beetle-affected forest, where live and dead trees are typically thoroughly mixed, has not been attempted before and should provide insight into the sensitivity of LiDAR to bark beetle effects on coniferous forest canopies.

\section{Methods}

\subsection{Study areas}

Areas of bark beetle-infested coniferous forests included in this study are from: 1) the Kenai Peninsula in Alaska (AK), 2) the Pinaleño Mountains of southeastern Arizona (AZ), 3) north-central Colorado (CO), 4) central Idaho (ID), and 5) central Oregon (OR). The commonality among these study areas is that both field plot and LiDAR data were collected at 
the time of an active beetle outbreak in mature coniferous forest with each study area having trees of variable age, height, and density. The range of bark beetle-induced mortality was also highly variable across the field plots, ranging from 0 to $100 \%$ mortality.

\subsection{Field plots}

Field plot locations in AZ, CO, and ID were selected using stratified random (CO and ID) or systematic (AZ) sampling designs within the bounds of the LiDAR acquisitions. All plots were of fixed radius with radii of $12.6 \mathrm{~m}$ in AZ ( $0.05 \mathrm{ha}), 8.0 \mathrm{~m}$ in CO (0.02 ha), and $11.3 \mathrm{~m}$ in ID (0.025 ha). Field plots in AK and OR were Forest Inventory and Analysis (FIA) plots at predetermined, systematic locations. In OR, these plots were augmented with USFS Region 6 (R6) Continuous Vegetation Survey (CVS) plots also situated along a systematic grid. Each FIA plot in AK and OR consists of 5 subplots of $7.3 \mathrm{~m}$ radius ( 0.11 ha total plot area) while the R6 plots in OR consist of 4 subplots of $15.5 \mathrm{~m}$ radius ( 0.38 ha total plot area). The subplot level data were combined and summarized at the plot level to preclude any issues of spatial autocorrelation, pseudo-replication, or inflated plot numbers. Live and Dead BA were summarized at the plot level from individual tree diameter at breast height (dbh) measurements and tree condition calls using the Forest Vegetation Simulator (FVS) while taking into account the different plot areas and then converted from English units of $\mathrm{ft}^{2} / \mathrm{ac}$ to metric units of $\mathrm{m}^{2} / \mathrm{ha}$.

\subsection{Data processing}

Metrics of the height, intensity, and density of LiDAR points within the fixed-radius field plots were calculated using the CloudMetrics tool of FUSION LiDAR visualization and analysis software (McGaughey 2012). In AK and OR, the LiDAR points within the individual subplots were extracted from the point cloud and concatenated into a single file prior to calculating plot-level metrics. In all study areas, ground elevations from the LiDAR-derived digital terrain model (DTM) were subtracted from the point elevations before calculating canopy metrics. A height threshold of breast height $(1.37 \mathrm{~m})$ was used to separate ground and understory returns from overstory returns. Height and intensity metrics were statistics based on the distributions of height and intensity values associated with each return: percentiles (minimum, median, maximum, quartiles and interquartile range (IQ)), mode, mean, standard deviation, variance, skewness, kurtosis, coefficient of variation (CV), average absolute deviation (AAD), and canopy relief ratio (CRR; Pike and Wilson 1971). Density metrics were calculated as the percentage of both $1^{\text {st }}$ and all returns $>1.37 \mathrm{~m}$ (breast height, $\mathrm{BH}$ ), mean, and mode; and within seven vertical height strata $0-6:<0.15 \mathrm{~m}, 0.15-1.37 \mathrm{~m}, 1.37-5 \mathrm{~m}, 5-10 \mathrm{~m}, 10-20 \mathrm{~m}, 20-30 \mathrm{~m}$, and $>30 \mathrm{~m}$. Twenty topographic metrics, including elevation, slope, transformed aspect, profile and planiform curvatures, slope* $\cos (\mathrm{asp})$, slope* $\sin (\mathrm{asp})$, and heatload index were also calculated from digital terrain models (DTM) after aggregating them to 30-m resolution, using an Imagine add-on tool developed at the USFS Remote Sensing Applications Center (Ruefenacht In Prep).

\subsection{Random Forests model development}

Predictor variables were selected from the suite of candidate metrics generated from either FUSION (canopy height, intensity, density metrics) or the Imagine tool (topographic metrics). RF calculates variable importance values based on the number of nodes it forms within the random forest of regression trees. Those predictors exhibiting the highest Model Improvement Ratio (MIR) calculated from standardized importance values were selected (Evans and Cushman 2009, Evans et al. 2010). RF randomly selects variable subsets through a bootstrapping procedure that makes it robust to highly correlated data and resistant to overfitting (Breiman 2001). However, in the interest of parsimony, we also eliminated predictors if they had a Pearson correlation $r>0.9$ with another predictor having a higher MIR value. RF randomly withholds one third of the data as an out-of-bag sample at every bootstrap iteration, so 
it is not necessary to partition the data into model and validation datasets (Breiman 2001).

\section{Results}

In the $\mathrm{AK}, \mathrm{AZ}$, and $\mathrm{OR}$ field plots, dead trees comprised less than half of the BA measured and were a low proportion of Total BA in AK and AZ, whereas in CO and ID, more than half of the plot-level BA was from dead trees (Table 1).

Table 1: Summary Statistics of Plot-Level Live and Dead Basal Area ( $\left.\mathrm{m}^{2} / \mathrm{ha}\right)$

\begin{tabular}{lcccccccc}
\hline \multirow{2}{*}{ Study area } & Plots & Response & Minimum & $1^{\text {st }}$ Quartile & Median & Mean & $3^{\text {rd }}$ Quartile & Maximum \\
\hline Alaska & \multirow{2}{*}{194} & Live BA & 0.0 & 4.1 & 8.6 & 12.6 & 18.7 & 62.3 \\
& & Dead BA & 0.0 & 0.0 & 1.5 & 3.9 & 5.7 & 24.5 \\
\multirow{4}{*}{ Arizona } & \multirow{2}{*}{101} & Live BA & 0.0 & 9.3 & 32.8 & 35.5 & 57.0 & 126.3 \\
& & Dead BA & 0.0 & 4.9 & 10.0 & 16.9 & 23.3 & 103.8 \\
Colorado & \multirow{2}{*}{113} & Live BA & 0.0 & 9.7 & 17.2 & 23.1 & 30.7 & 110.6 \\
& & Dead BA & 0.0 & 36.8 & 50.8 & 54.9 & 70.6 & 126.7 \\
\multirow{4}{*}{ Idaho } & \multirow{2}{*}{27} & Live BA & 5.0 & 8.7 & 14.3 & 15.3 & 21.2 & 29.5 \\
& & Dead BA & 3.0 & 11.6 & 17.6 & 18.6 & 23.6 & 43.7 \\
\multirow{2}{*}{ Oregon } & \multirow{2}{*}{190} & Live BA & 0.0 & 10.4 & 16.6 & 20.3 & 28.1 & 99.9 \\
& & Dead BA & 0.0 & 0.0 & 1.4 & 3.3 & 4.3 & 27.2 \\
\hline
\end{tabular}

Metrics of all types (height, intensity, density, and topographic) were selected based on MIR for the RF models (Table 2). In general, height and density metrics were most important in predicting Live and Total BA, whereas intensity metrics were most important in predicting Dead, \%Live, and \%Dead BA. An exception was OR, where intensity metrics were not important, perhaps because the dead trees comprised the lowest proportion of Total BA of any study area. Topographic metrics were generally the least important metrics in all models. Because intensity values could not be normalized across all study areas, we also tested the effect of omitting intensity metrics from the models; the result (not shown) was more density metrics selected in place of intensity metrics, but generally a lower number of selected predictors overall, and lower variance explained in all study areas except OR. Intensity metrics were more important in explaining Live BA in CO and ID, where tree mortality was higher, than in AK, AZ and OR. In AK, AZ, CO, and ID, RF Models predicting \%Live and \%Dead BA were almost identical in terms of important variables (Table 2) and variance explained (Table 3), which is not surprising because these responses are mutually dependent. In OR, where sampled tree mortality was lowest, RF models predicting \%Live and \%Dead BA were not identical.

In all study areas, the RF models explained more variance in Live BA than Dead BA (Table 3). In $\mathrm{AK}, \mathrm{AZ}, \mathrm{CO}$, and ID, intensity metrics were very effective predictors of \%Live and \%Dead BA; omitting intensity metrics (not shown) reduced variance explained, especially for predicting dead BA. Models of \%Live and \%Dead BA explained more variance (51.2- 74.0\% variance explained) than models predicting absolute Live, Dead, and Total BA (17.1- 67.9\% variance explained) in these areas. In OR, where tree mortality was lowest and intensity metrics were comparatively unimportant, \%Live and \%Dead BA models explained less variance (13.6-24.5\% variance explained) than RF models predicting absolute Live and Dead BA (27.3$59.1 \%$ variance explained). In AK, CO, ID, and OR, RF models predicting Total BA explained more variance than RF models predicting Live and Dead BA. The variance explained by RF for predicting Total BA in AZ was intermediate to that of predicting Live and Dead BA. In all study areas, omitting intensity metrics (not shown) did not greatly affect variance explained by RF 
models predicting Total BA.

Table 2: LiDAR Metrics Selected for RF Models Based on MIR and Pearson $r<0.9$

\begin{tabular}{|c|c|c|c|c|c|}
\hline $\begin{array}{c}\text { Study } \\
\text { area }\end{array}$ & Response & Height & Intensity & Density & Topographic \\
\hline \multirow[t]{5}{*}{ Alaska } & Live BA & Mode, $10^{\text {th }}$ & $\mathrm{CV}$ & $\% 1^{\text {st }}>$ Mean, Strat 0 & Elev \\
\hline & Dead BA & Max, CRR & Mean, StDev, CV & Strat4 & Elev \\
\hline & Total BA & Max, Mode, $30^{\text {th }}$ & Max & $\begin{array}{c}\% 1^{\text {st }}>\text { Mean, Strat } 0, \\
\text { Strat } 4\end{array}$ & Elev \\
\hline & \%Live BA & $\begin{array}{l}\text { Mean, StDev, CV, } \\
\text { Skew, CRR }\end{array}$ & $\begin{array}{l}\text { Mean, StDev, CV, } \\
\text { Skew, Kurt }\end{array}$ & $\% 1^{\text {st }}>$ Mean, Strat 4 & Elev \\
\hline & $\%$ Dead BA & $\begin{array}{l}\text { Mean, StDev, CV, } \\
\text { Skew, CRR }\end{array}$ & $\begin{array}{l}\text { Mean, StDev, CV, } \\
\text { Skew, Kurt }\end{array}$ & $\% 1^{\text {st }}>$ Mean, Strat 4 & Elev \\
\hline \multirow[t]{5}{*}{ Arizona } & Live BA & $\begin{array}{c}\text { Mean, Mode, CV, } \\
10^{\text {th }}, \text { CRR }\end{array}$ & StDev, Skew & $\begin{array}{l}\% \text { All }>\text { BH, Strat } 0, \\
\text { Strat2 }\end{array}$ & Elev \\
\hline & Dead BA & $\begin{array}{l}\text { Mean, Mode, CV, } \\
\text { IQ, Skew }\end{array}$ & $\begin{array}{l}\text { Max, Mean, } \\
\text { Skew, Kurt }\end{array}$ & $\begin{array}{c}\% 1^{\text {st }}>\mathrm{BH}, \% \text { All }>\text { Mode, } \\
\text { Strat1 }\end{array}$ & $\begin{array}{c}\text { Elev, } \\
\text { SlpCosAsp }\end{array}$ \\
\hline & Total BA & $\begin{array}{l}\text { Mean, Mode, CV, } \\
10^{\text {th }}, \text { CRR }\end{array}$ & StDev, Kurt & $\begin{array}{c}\% 1^{\text {st }}>\text { BH, } \% \text { All }>\text { Mode, } \\
\text { Strat } 0, \text { Strat } 2, \\
\text { Strat } 3 \text {, Strat } 4\end{array}$ & Elev \\
\hline & \%Live BA & $\begin{array}{l}\text { Mode, CV, } 5^{\text {th }}, \\
\text { CRR }\end{array}$ & $\begin{array}{l}\text { Mean, Skew, } \\
\text { Kurt, AAD }\end{array}$ & $\% 1^{\text {st }}>\mathrm{BH}$ & Elev \\
\hline & $\%$ Dead BA & $\begin{array}{l}\text { Mode, CV, } 5^{\text {th }}, \\
\text { CRR }\end{array}$ & $\begin{array}{l}\text { Mean, Skew, } \\
\text { Kurt, AAD }\end{array}$ & $\% 1^{\text {st }}>\mathrm{BH}$ & Elev \\
\hline \multirow[t]{5}{*}{ Colorado } & Live BA & $\begin{array}{l}\text { Max, Mean, Mode, } \\
\text { Skew, 5th }\end{array}$ & Mean, Kurt & $\begin{array}{c}\% 1^{\text {st }}>\text { BH, Strat } 2, \\
\text { Strat } 4\end{array}$ & $\begin{array}{l}\text { Heatload, } \\
\text { Slope }\end{array}$ \\
\hline & Dead BA & Mean, $99^{\text {th }}$ & Skew & $\begin{array}{c}\% 1^{\text {st }}>\text { BH, } \% 1^{\text {st }}>\text { Mode, } \\
\text { Strat } 4\end{array}$ & Elev \\
\hline & Total BA & Max, Mean, $25^{\text {th }}$ & Max, Mean & $\begin{array}{c}\% \text { All }>\text { BH, } \% 1^{\text {st }}>\text { Mode } \\
\text { Strat } 4, \text { Strat } 5\end{array}$ & Elev \\
\hline & $\%$ Live BA & Min, Kurt & $\begin{array}{l}\text { Mean, CV, Skew, } \\
\text { Kurt }\end{array}$ & - & Slope \\
\hline & $\%$ Dead BA & Min, Kurt & $\begin{array}{c}\text { Mean, CV, Skew, } \\
\text { Kurt }\end{array}$ & - & Slope \\
\hline \multirow[t]{5}{*}{ Idaho } & Live BA & $\operatorname{Max}, \mathrm{CV}, 1^{\mathrm{st}}$ & CV, IQ, Kurt & $\begin{array}{c}\text { \%All }>\text { BH, \%All }>\text { Mode, } \\
\text { Strat1, Strat } 4 \text {, Strat5 }\end{array}$ & Elev \\
\hline & Dead BA & Mode, Skew, $30^{\text {th }}$ & $\begin{array}{l}\text { Max, Mean, } \\
\text { Skew, AAD }\end{array}$ & $\% 1^{\text {st }}>$ Mode, Strat 1 & $\begin{array}{l}\text { Elev, Slope, } \\
\text { SlpCosAsp }\end{array}$ \\
\hline & Total BA & $\begin{array}{l}\text { Min, Max, Skew, } \\
\text { AAD, } 40^{\text {th }}, 75^{\text {th }}\end{array}$ & - & $\%$ All $>$ Mean, Strat5 & - \\
\hline & $\%$ Live BA & $1^{\text {st }}$ & CV, IQ, Kurt & Strat1 & Elev \\
\hline & $\%$ Dead BA & $1^{\text {st }}$ & CV, IQ, Kurt & Strat1 & Elev \\
\hline \multirow[t]{5}{*}{ Oregon } & Live BA & $\begin{array}{l}\text { Mean, } 20^{\text {th }}, 95^{\text {th }} \text {, } \\
\text { CRR }\end{array}$ & Mean, Kurt, AAD & \%All $>$ BH, Strat4 & Elev \\
\hline & Dead BA & $\begin{array}{l}\text { Mean, Kurt, } 1^{\text {st }} \\
99^{\text {th }}\end{array}$ & Mean, CV & $\%$ All $>$ BH, Strat6 & Elev \\
\hline & Total BA & $\begin{array}{c}\text { Mean, CV, Kurt, } \\
\text { AAD }\end{array}$ & Mode, CV, Kurt & $\%$ All $>$ BH, Strat 4 & Elev \\
\hline & \%Live BA & $\begin{array}{l}\text { Mean, Skew, Kurt, } \\
95^{\text {th }}, \text { CRR }\end{array}$ & $\begin{array}{l}\text { Mean, Mode, } \mathrm{CV} \text {, } \\
\text { Kurt }\end{array}$ & $\begin{array}{c}\% \text { All }>\text { BH, } \% \text { All }>\text { Mean, } \\
\text { Strat } 2, \text { Strat } 3\end{array}$ & - \\
\hline & $\%$ Dead BA & $\begin{array}{c}\text { Mode, CV, IQ, } 1^{\text {st }}, \\
99^{\text {th }}, \text { CRR }\end{array}$ & StDev, Skew, Kurt & $\begin{array}{c}\% \text { All }>\text { BH, } \% \text { All }>\text { Mean, } \\
\text { Strat } 2, \text { Strat } 3\end{array}$ & - \\
\hline
\end{tabular}

Table 3: \% Variance Explained by RF to Predict Plot-Level Basal Area Responses 


\begin{tabular}{|c|c|c|c|}
\hline Study area & Response & Number of predictors & $\%$ Variance explained \\
\hline \multirow[t]{5}{*}{ Alaska } & Live BA & 6 & 67.2 \\
\hline & Dead BA & 7 & 46.1 \\
\hline & Total BA & 8 & 67.9 \\
\hline & \%Live BA & 13 & 59.7 \\
\hline & $\%$ Dead BA & 13 & 59.1 \\
\hline \multirow[t]{5}{*}{ Arizona } & Live BA & 11 & 50.2 \\
\hline & Dead BA & 14 & 17.1 \\
\hline & Total BA & 15 & 34.9 \\
\hline & \%Live BA & 10 & 74.0 \\
\hline & $\%$ Dead BA & 10 & 73.4 \\
\hline \multirow[t]{5}{*}{ Colorado } & Live BA & 12 & 44.3 \\
\hline & Dead BA & 7 & 39.4 \\
\hline & Total BA & 10 & 57.5 \\
\hline & \%Live BA & 7 & 51.6 \\
\hline & $\%$ Dead BA & 7 & 51.2 \\
\hline \multirow[t]{5}{*}{ Idaho } & Live BA & 12 & 58.0 \\
\hline & Dead BA & 12 & 41.4 \\
\hline & Total BA & 8 & 58.9 \\
\hline & \%Live BA & 6 & 67.7 \\
\hline & $\%$ Dead BA & 6 & 67.7 \\
\hline \multirow[t]{5}{*}{ Oregon } & Live BA & 10 & 59.1 \\
\hline & Dead BA & 9 & 27.3 \\
\hline & Total BA & 10 & 66.0 \\
\hline & \%Live BA & 13 & 24.5 \\
\hline & $\%$ Dead BA & 13 & 13.6 \\
\hline
\end{tabular}

\section{Discussion}

We attribute the lower variance explained for Dead BA compared to Live BA to greater penetration of the canopy by laser pulses after needles drop from dead trees, and thus a lesser amount of information than would be reflected from a green or red canopy of the same height. Tree condition calls (live or dead) at the time of field plot characterization did not coincide with the time of LiDAR acquisition; thus, we do not know whether dying or dead trees were green, red, or grey when the LiDAR was collected. Temporal mismatches between field and LiDAR data collections are likely greater in AK and OR, because only some FIA or CVS plots are characterized in a given year.

Based on this preliminary analysis, we conclude that it may be difficult to generalize a consistent subset of LiDAR metrics that work across these different affected forest ecosystems to predict bark beetle effects on BA. It is more likely that we may be able to generalize analytical approaches, if not specific metrics. In future work, we will include disturbance vectors derived from Landsat image time series in the analysis, to more accurately predict the BA response variables. Integrating temporal disturbance vectors from Landsat with airborne LiDAR metrics that capture fine spatial detail should prove a more powerful approach for predicting canopy structure effects of bark beetle-induced tree mortality. 


\section{Conclusion}

This analysis tested the feasibility of predicting both Live and Dead BA in bark beetle-affected coniferous forests from discrete-return LiDAR. We found that LiDAR-derived height, intensity, density, and topographic metrics explained more variance in Live BA than Dead BA, and usually the most variance in Total BA, which we conclude is due to the greater sensitivity of LiDAR to needled trees than to grey trees.

\section{Acknowledgements}

Funding was provided by the Special Technology Development Program of the U.S. Forest Service Forest Health Protection division. Funding to the University of Idaho was through Joint Venture Agreement 11-JV-11221633-184.

\section{References}

Breiman, L., 2001. Random forests. Machine Learning, 45, 5-32.

Bright, B.C., Hicke, J.A. and Hudak, A.T. 2012. Estimating aboveground carbon stocks of a forest affected by mountain pine beetle in Idaho using lidar and multispectral imagery. Remote Sensing of Environment, 124: 270-281.

Coops, N.C., Varhola, A., Bater, C.W., Teti, P. Boon, S., Goodwin, N., and Weiler, M., 2009. Assessing differences in tree and stand structure following beetle infestation using lidar data. Canadian Journal of Remote Sensing, 35: 497-508.

Evans, J.S. and Cushman, S.A., 2009. Gradient modeling of conifer species using Random Forests. Landscape Ecology, 5, 673-683.

Evans, J.S., Murphy, M.A., Holden, Z.A. and Cushman, S.A., 2010. Modeling species distribution and change using Random Forests. In: C.A. Drew, F. Huettmann, Y. Wiersma (Eds.). Chapter 8 in Predictive Modeling in Landscape Ecology. Springer.

Hicke, J.A., Allen, C.D., Desai, A.R., Dietze, M.C., Hall, R.J., Hogg, E.H., Kashian, D.M., Moore, D., Raffa, K.F., Sturrock, R.N. and Vogelmann, J., 2012. Effects of biotic disturbances on forest carbon cycling in the United States and Canada. Global Change Biology, 18, 7-34.

Hudak, A.T., Strand, E.K., Vierling, L.A., Byrne, J.C., Eitel, J., Martinuzzi, S. and Falkowski, M.J., 2012. Quantifying aboveground forest carbon pools and fluxes from repeat LiDAR surveys. Remote Sensing of Environment, 123: 25-40.

Kim, Y., Yang, Z., Cohen, W.B., Lauver, C.L., and Vankat, J.L., 2009. Distinguishing between live and dead standing tree biomass on the North Rim of Grand Canyon National Park, USA using small-footprint lidar data. Remote Sensing of Environment, 113: 2499-2510.

Kurz, W.A., Dymond, C.C., Stinson, G., Rampley, G.J., Neilson, E.T., Carroll, A.L., Ebata, T. and Safranyik, L. 2008. Mountain pine beetle and forest carbon feedback to climate change. Nature, 452, 987-990.

McGaughey, R.J., 2012. FUSION/LDV: Software for LIDAR Data Analysis Visualization. USDA Forest Service, Pacific Northwest Research Station. 170 p.

Negron, J.F., Allen, K., Cook, B. and Withrow, J.R. Jr., 2008. Susceptibility of ponderosa pine, Pinus ponderosa (Dougl. Ex Laws.), to mountain pine beetle, Dendroctonus ponderosae Hopkins, attack in uneven-aged stands in the Black Hills of South Dakota and Wyoming USA. Forest Ecology and Management, 254: 327-334.

Pfeifer, E.M., Hicke, J.A., and Meddens, A.J.H., 2011. Observations and modeling of aboveground tree carbon stocks and fluxes following a bark beetle outbreak in the western United States. Global Change Biology, 17, 339-350.

Pike, R.J. and Wilson, S.E., 1971. Elevation relief ratio, hypsometric integral, and geomorphic area altitude analysis. Bulletin of the Geological Society of America, 82, 1079-1084.

Ruefenacht, B. (In Prep) Digital elevation model derivatives. USDA Forest Service Remote 
SilviLaser 2012, Sept. 16-19 September 2012 -Vancouver, Canada

Sensing Applications Center, Salt Lake City, Utah. 